\title{
Características da Psicologia do Trabalho e das Organizações na Formação do Psicólogo no Brasil
}

\author{
Fellipe Coelho-Lima \\ Pedro Fernando Bendassolli \\ Oswaldo Hajime Yamamoto \\ Universidade Federal do Rio Grande do Norte \\ Natal, RN, Brasil
}

\begin{abstract}
RESUMO
Este artigo analisa a participação e as características dos conteúdos da Psicologia do Trabalho e das Organizações (PT\&O) presentes na formação do psicólogo brasileiro após as novas Diretrizes Curriculares Nacionais. Para isso, os projetos pedagógicos de 43 cursos de Psicologia de diversas regiões e origens administrativas passaram por análise documental, sendo a amostra construída por conveniência. Como principais resultados, encontrou-se que 41 cursos citaram a PT\&O na definição do seu perfil de egresso ou no processo de formação do psicólogo; todos os cursos possuíam ao menos uma disciplina desse campo, ocupando uma média de $10 \%$ da carga horária; e que a PT\&O é vinculada às discussões de qualidade de vida e saúde do trabalhador, pensada para locais como empresas, políticas públicas e sindicatos. Além de apresentar uma ampla variedade temática, esses resultados sugerem que a PT\&O ocupa um lugar relevante na formação em psicologia no Brasil.
\end{abstract}

Palavras- chaves: Psicologia organizacional; Formação do psicólogo; Análise de conteúdo.

\section{ABSTRACT}

Work and Organizational Psychology's Characteristics in the Brazilian Undergraduate Education in Psychology

This paper aims to analyse the presence of Work and Organizational Psychology (WOP) in the Brazilian psychological training after the changes brought about by new National Curricular Guidelines. A convenience sample of 43 pedagogical projects from public and private higher education institutions throughout Brazil was submitted to a documental analysis. As results, WOP was found to be mentioned in 41 courses, specifically in the context of graduates' student profiles and their training as psychologists. All the courses require students to enroll in at least one class in WOP, which is equivalent to $10 \%$ of the total training workload. The analysis showed that WOP is related to discussions concerning quality of life and worker health in such contexts as organizations, public policies and unions. In addition to recovering a wide thematic diversity, the findings suggest that WOP has an important place in the training of psychologists in Brazil.

Keywords: Organizational psychology; Psychologist education; Content analysis.

\section{RESUMEN}

\section{Características de la Psicología del Trabajo y de las Organizaciones en la Formación del Psicólogo en Brasil}

El presente artículo examina la participación y características de los contenidos de Psicología del Trabajo y las Organizaciones (PT \& O) en la formación del psicólogo brasileño después de las nuevas "Diretrizes Curriculares Nacionais". Una muestra de conveniencia resultó en 43 instituciones de diferentes regiones del país y con distintas estructuras administrativas, cuyos proyectos educativos pasaron por análisis documental. Los principales resultados son que 41 cursos citaron la PT\&O en su definición de perfil del egreso o en el proceso de formación del psicólogo; todos los cursos poseían por lo menos una asignatura de este campo, ocupando un porcentaje de $10 \%$ de la carga horaria; la PT\&O es vinculada a las discusiones de calidad de vida y salud del trabajador, pensada para empresas, políticas públicas y sindicatos. Además de presentar una amplia gama temática, estos resultados sugieren que PT\&O ocupa un lugar destacado en la formación del psicólogo en Brasil.

Palabras clave: Psicologia de las organizaciones; Formacion del psicologo; Analisis de contenido. 
Em 2004, iniciou-se um processo agudo de transformação na formação dos psicólogos no Brasil, impulsionado pela promulgação das Diretrizes Nacionais para o Curso (DCN) de Psicologia na forma do Parecer CNE/CES no 62/2004. Posteriormente, em 2011, esse texto foi modificado na seção específica acerca da licenciatura.

As diretrizes são o produto histórico de diversos debates no interior da Psicologia. Por exemplo, alguns estudos mostravam que havia, antes dessas mudanças, uma incapacidade dos cursos em atender às demandas emergentes da realidade brasileira, notadamente por sua precariedade e caráter elitista (Seixas, 2014). Por conta de denúncias como essas, já na década de 1990 levantou-se a necessidade de uma reestruturação do processo de formação graduada do psicólogo (Rocha Jr., 1999). Adicionalmente, a legislação que regia o Ensino Superior passava por mudanças, na medida em que se operacionalizavam as determinações da nova Lei de Diretrizes e Bases da Educação Nacional (LDB), de 1996.

As mudanças operadas pelas DCN abriram espaço para responder às diversas críticas feitas até então sobre a formação em Psicologia. As novidades consistiam em propor o atendimento a determinados eixos temáticos (sete ao total), em vez de prescrever as disciplinas que deveriam compor os cursos. A matriz curricular seria dividida em dois momentos: o núcleo comum, no qual os graduandos teriam os conhecimentos básicos da Psicologia, e as ênfases curriculares, quando os discentes poderiam aprofundar os seus conhecimentos em alguns domínios específicos da Psicologia. O estágio ganhou maior destaque, devendo perfazer o mínimo de $15 \%$ da carga horária total e ser distribuído nos dois momentos do curso. Além disso, passou se a priorizar o desenvolvimento de competências, em detrimento de conteúdos específicos (CNE/CES 2004).

Nesse contexto de reformulação, também contribuíram discussões específicas sobre o modo como a Psicologia do Trabalho e das Organizações (PT\&O) estava sendo integrada aos cursos de graduação de Psicologia. Estudos como os de Bastos, Martins, Tironi e Silveira (1988), Iema (1999) e Zanelli (1986, 1995) e, mais recentemente, Botelho (2003), Campos e Romaro (2008), Freitas (2002) e Morello Filho (2004), chegaram, por caminhos distintos, a conclusões preocupantes sobre essa questão. Primeiramente, o espaço para tratar dos tópicos pertencentes a esse campo era diminuto, considerando o total de disciplinas das matrizes curriculares (Bastos, Martins, Tironi \& Silveira, 1988; Iema, 1999; Morello Filho, 2004). Dentro desse pequeno reduto, os assuntos da $\mathrm{PT} \& \mathrm{O}$ eram abordados de maneira acrítica, recorrendo a modismo tecnicista e gerencial com a ausência de reflexões políticas e filosóficas sobre as teorias e técnicas tratadas pela PT\&O (Zanelli, 1986; 1995). Por fim, constatou-se a defasagem entre os conteúdos da PT\&O abordados nos cursos e a produção de conhecimento realizada por esse campo (Botelho, 2003; Freitas, 2002; Iema, 1999; Zanelli, 1995). Esses elementos acabaram por revelar um hiato entre a preparação dentro da PT\&O na formação graduada do psicólogo, e as demandas sociais com as quais esse profissional deveria enfrentar ao sair da Academia.

É importante notar que, para além de problemas internos ao modo como a PT\&O é integrada aos cursos de formação de psicólogos, o próprio campo científico profissional passou, ao longo do tempo, por mudanças significativas que exigiam a atualizações desses cursos. Esse campo da Psicologia é compreendido como aquele que trata dos elementos relacionados à relação do ser humano com o trabalho. Considerando o contexto brasileiro, autores como Borges, Oliveira e Morais (2005), Zanelli e Bastos (2004) e Sampaio (1998) sugerem que o desenvolvimento da PT\&O pode ser analisado conforme a sucessão histórica de tópicos investigados e intervenções realizadas no campo. Com base nessa análise, seria possível agrupar as temáticas em três momentos históricos: a Psicologia Industrial, a Psicologia Organizacional e a Psicologia do Trabalho.

Embora possa haver diferentes interpretações acerca do desenvolvimento histórico do campo, é indiscutível a consideração de que este passa por uma intensa complexificação. Esse fato é observável tanto pela expansão dos temas abordados, dos lugares em que esses conhecimentos podem ser aplicados e das ações empreendidas, como pelo compromisso ideológico e político que o psicólogo assume em cada um deles. Portanto, seria de se esperar que essa maior complexidade se refletisse nos conteúdos e no processo formativo do psicólogo brasileiro.

Assumindo os debates colocados nas linhas anteriores, referentes às transformações ocorridas no interior da formação do psicólogo e do campo científico-profissional da $\mathrm{PT} \& \mathrm{O}$, faz-se necessário pesquisar sobre o lugar da PT\&O na formação graduada do psicólogo. O presente trabalho se propôs a analisar como a Psicologia do Trabalho e das Organizações está retratada na formação graduada do psicólogo, após a implantação das Diretrizes Curriculares Nacionais.

\section{Procedimentos Metodológicos}

Se o disparador dessa pesquisa é a dúvida sobre a forma que a PT\&O se apresenta na formação do 
psicólogo atualmente, a construção de uma possível resposta perpassava pela compreensão na forma que esses cursos estão organizados. Desse modo, optou-se por empreender uma análise dos Projetos Pedagógicos de Curso (PPC), por esses documentos sintetizarem os princípios que regem a formação do psicólogo em cada curso, possuindo uma maior projeção ao longo do tempo (Seixas, Coelho-Lima, Silva \& Yamamoto, 2013).

Considerando o grande número de cursos de Psicologia à época da realização da definição do corpus desta pesquisa (460 cursos), optou-se, com o objetivo de garantir parcimônia e manejo analítico, pela escolha de apenas um curso por instituição de ensino superior (IES), e pela exclusão dos que ainda não haviam formado psicólogos a partir de currículo elaborado conforme as novas DCNs.

Com isso, chegou-se ao total de 276 cursos e iniciou-se o levantamento exaustivo das informações pertinentes à pesquisa. Para tanto, realizouse visitas aos sites institucionais e contataram-se as coordenações dos cursos em quatro momentos - duas vezes por correio eletrônico (e-mail) e duas vezes por telefone, sendo possível, ao final de um semestre, obter-se o retorno de 43 cursos. Trata-se, pois, de uma amostragem por conveniência de tipo espontâneo que conseguiu construir um corpus que resgatou as principais características do conjunto total de curso de Psicologia no Brasil, segundo uma análise post hoc permitiu a constatação. Esse corpus é composto por universidades (31 cursos, 72,1\%), faculdades (oito cursos, $18,6 \%$ ) e centros universitários (quatro cursos, $9,3 \%$ ); vinculados a iniciativa pública ( 25 cursos, $58,1 \%$ ) e privada (18 cursos, $41,9 \%$ ), e originários da região sudeste ( 16 cursos, 37,2\%), nordeste (13 cursos, $30,2 \%$ ), sul (nove cursos, $20,9 \%$ ), centro-oeste (quatro cursos, 9,3\%) e norte (um curso, 2,3\%).

Para a análise dos documentos, utilizaram-se os procedimentos desenvolvidos por Seixas, CoelhoLima, Silva e Yamamoto (2013). Segundo esses autores, os PPCs são compostos por três tipos de materiais: textos descritivos do curso, matriz curricular e ementas. Como consta na Tabela 1, o primeiro tipo de material está organizado em três blocos de informações, seguidos de suas respectivas categorias.

A partir da organização dos PPCs de acordo com essa matriz analítica, procedeu-se à identificação dos trechos dos textos que versavam especificamente sobre a PT\&O. O processo de busca por esses conteúdos nos PPCs foi referenciado pela literatura científica que trata da PT\&O sob a ótica da prática profissional, da produção científica e do desenvolvimento histórico desse campo. Esses trabalhos, por sua vez, foram compilados previamente, de forma sistemática, e revisados pelos pesquisadores para fundamentar essa etapa da pesquisa.

TABELA 1

Blocos analíticos do Projeto Pedagógico de Curso

\begin{tabular}{lll}
\hline \multicolumn{1}{c}{ Bloco } & \multicolumn{1}{c}{ Categoria } & \multicolumn{1}{c}{ Definição } \\
\hline $\begin{array}{l}\text { I - Fundamentos teóricos, } \\
\text { filosóficos e pedagógicos }\end{array}$ & Perfil do egresso & $\begin{array}{l}\text { Características e competências prescritas para o profissional que o curso } \\
\text { pretende formar }\end{array}$ \\
& $\begin{array}{l}\text { Processo formativo } \\
\text { Justificativa do curso }\end{array}$ & $\begin{array}{l}\text { Estratégias utilizadas pelo curso para alcançar o perfil do egresso } \\
\text { Motivos e demandas para a criação do curso }\end{array}$ \\
& Histórico do curso & Aspectos históricos da formação do psicólogo no curso \\
II - Ênfases curriculares e & Perfil do egresso da ênfase & Características e competências prescritas para o profissional formado na ênfase \\
disciplinas & curricular & curricular específica \\
& Processo formativo na ênfase & Procedimentos utilizados durante o período da ênfase para alcançar o perfil do \\
& curricular & egresso da ênfase curricular \\
& Justificativa da ênfase curricular & Motivos e demandas atendidas pela criação da ênfase curricular \\
& Funcionamento da ênfase & Articulação da ênfase com os outros momentos do curso \\
Locais de prática profissional & Espaços previstos para realização das práticas profissionais \\
& Funcionamento dos estágios & Modo como é concebida a rotina de trabalho nos estágios básicos e específicos \\
& Relação entre os estágios & Estratégias de diálogo entre os estágios básicos e específicos \\
& Objetivos dos estágios & Finalidade pensada para os estágios básicos e específicos \\
& Atividades previstas & Elenca as práticas profissionais previstas na formação do psicólogo
\end{tabular}

Fonte: Adaptado de Seixas, Coelho-Lima, Silva e Yamamoto (2013). 
Após organizar os PPCs de acordo com as categorias da Tabela 1 e selecionar, dentro dessa primeira categorização, quais os trechos que versavam sobre a PT\&O, empreendeu-se a leitura exaustiva desse conteúdo, com a finalidade de se levantar novas categorias específicas sobre as concepções da PT\&O utilizadas pelos cursos. Essa categorização seguiu um processo contínuo, no qual se partiu de categorias simples e imediatas até alcançar-se um nível de generalidade suficiente para agrupar o conteúdo dos trechos.

Para o tratamento da matriz curricular e ementas, procedeu-se com a seleção dos componentes curriculares que se relacionavam com a PT\&O. Para essa etapa, utilizou-se uma lista de temas pertencentes a esse campo da Psicologia construída a partir da literatura utilizada na etapa anterior. Essa listagem qual guiou a classificação das disciplinas de acordo com o seu grau de vinculação à $\mathrm{PT} \& \mathrm{O}$, identificado a partir da leitura de seus títulos e ementas.

Após a compilação das disciplinas ligadas a esse campo, realizou-se uma dupla análise. A primeira, relativa às características da matriz curricular, ou seja, quantidade de disciplinas e a carga horária delas. Ainda, seguindo orientação de Seixas, Coelho-Lima, Silva e Yamamoto (2013), agregou-se, nesse momento, a classificação das disciplinas quanto a que eixos estruturantes da DCN as disciplinas respondiam. A Tabela 2 explicita as definições adotadas para cada um desses eixos.

A segunda análise tomou os temas identificados nas disciplinas - por meio da leitura das ementas - para verificar quais fases da PT\&O são predominantes nas disciplinas desse campo.
Os dados oriundos de todas as etapas ou foram organizadas em software especializado em tratamento de materiais textuais (no caso dos textos descritivos do PPC) ou em planilha eletrônica (quando da análise da matriz curricular), viabilizando a compreensão da realidade de cada curso e a comparação entre eles.

\section{RESULTADOS E DISCUSSÃO}

A partir do processo de análise descrito anteriormente, foi possível levantar algumas informações importantes para a compreensão da forma que a PT\&O está integrada à graduação em Psicologia. Um primeiro indício é em que momento do PPC se realiza alusões a esse campo. Portanto, é revelador que a PT\&O esteja presente, mais fortemente, no Bloco I, em processo formativo $(65,1 \%)$ e o perfil de egresso do curso (58,1\%); no Bloco II, em perfil do egresso da ênfase $(46,5 \%)$ e processo formativo nas ênfases curriculares (23,3\%); e no Bloco III, em atividades previstas (27,9\%) e locais de prática profissional (25,6\%).

$\mathrm{O}$ resgate da $\mathrm{PT} \& \mathrm{O}$ no momento em que se descrevem as diretrizes gerais do curso, no Bloco I, demostra que esse campo alcança um status de grande importância, seja por compor o seu processo de formação como um todo, seja por integrar diretamente a caracterização do tipo de profissional que pretende se formar. Corrobora com essa afirmação, além dos dados já apresentados, o fato de que apenas quatro cursos não fizeram alusão à PT\&O no Bloco I do PPC. Também quando se observa as descrições específicas para as ênfases curriculares, mais uma vez esse campo ganha destaque, não só por estarem previstas competências

TABELA 2

Definições dos eixos estruturantes das Diretrizes Curriculares Nacionais utilizadas na pesquisa

\begin{tabular}{ll}
\hline \multicolumn{1}{c}{ Nome do eixo estruturante } & \multicolumn{1}{c}{ Definição operacional utilizada na pesquisa } \\
\hline $\begin{array}{l}\text { Eixo A } \\
\text { Fundamentos epistemológicos e históricos }\end{array}$ & $\begin{array}{l}\text { Incluem as discussões que resgatam componentes históricos e/ou epistemológicos do } \\
\text { conteúdo tratado na disciplina, seja da Psicologia como ciência ou profissão, de um campo } \\
\text { da Psicologia, um tema, objeto, procedimento, técnica ou qualquer outro tipo de material } \\
\text { Participam os conteúdos que tratam de pressupostos teóricos e/ou metodológicos mais } \\
\text { amplos. Costumeiramente, são pressupostos aplicáveis a temas, objetos, técnicas e estratégias } \\
\text { de intervenção específicas }\end{array}$ \\
$\begin{array}{l}\text { Eixo B } \\
\text { Fundamentos teórico-metodológicos }\end{array}$ & $\begin{array}{l}\text { É composto pela apresentação de técnicas, estratégias, procedimentos ou qualquer arcabouço } \\
\text { instrumental para o processo de pesquisa e intervenção em Psicologia }\end{array}$ \\
$\begin{array}{l}\text { Eixo C } \\
\text { Procedimentos para a investigação científica } \\
\text { e a prática profissional }\end{array}$ & $\begin{array}{l}\text { Abarca as discussões a respeito de objetos específicos com que a Psicologia lida } \\
\text { Eixo D }\end{array}$ \\
Fenômenos e processos psicológicos & $\begin{array}{l}\text { São os conteúdos eminentemente de outros campos do saber e que historicamente não foram } \\
\text { apropriados pela Psicologia } \\
\text { Eixo E }\end{array}$ \\
Interfaces com campos afins do conhecimento incluídas as disciplinas que prevêem, explicitamente, alguma atividade prática ou \\
Eixo F \\
Práticas profissionais
\end{tabular}

Fonte: Adaptado de Seixas, Coelho-Lima, Silva e Yamamoto (no prelo). 
relacionadas a ele ou fazer parte do processo de formação nas ênfases, mas também por 28 cursos, $65,1 \%$, adotarem ênfases ligadas à PT\&O. Porém, no Bloco III - referente às práticas profissionais realizadas no curso -, ainda que se mantenha a tendência da PT\&O aparecer como um subdomínio relevante, há uma grande dispersão nas categorias que surgem, indicando uma pulverização dessas diretrizes. Com isso, evidenciase a relevância da $\mathrm{PT} \& \mathrm{O}$ na estruturação dos cursos não só nos momentos necessariamente específicos (como apresenta o conteúdo do Bloco II), mas nas diretrizes mais gerais. Contudo, os cursos analisados revelam dificuldades em derivar dessas orientações, recomendações específicas para o tópico da prática profissional ${ }^{1}$.

O modo como está organizada a matriz curricular desses cursos adensa ainda mais a afirmação de que esse campo da Psicologia possui um espaço relevante na formação do psicólogo. Nessa direção, constatou-se que todos os cursos possuíam ao menos uma disciplina de PT\&O, tendo sido compilados 246 componentes curriculares, os quais se distribuem como indicado na Tabela 3.

TABELA 3

Aspectos da matriz curricular relacionada à $\mathrm{PT} \& \mathrm{O}$

\begin{tabular}{lcc}
\hline & $N^{o}$ & $\%$ \\
\hline Quantidade de disciplinas vinculadas à PT\&O & & \\
De 01 a 03 & 13 & 30,2 \\
De 04 a 06 & 16 & 37,2 \\
De 07 a 09 & 9 & 20,9 \\
De 10 a 12 & 2 & 4,7 \\
De 13 a 15 & 3 & 7,0 \\
Carga horária das disciplinas vinculadas à PT\&O & \\
De 30h a 200h & 12 & 27,9 \\
De 201h a 400h & 12 & 27,9 \\
De 401h a 600h & 05 & 11,6 \\
De 601h a 800h & 07 & 16,3 \\
De 801h a 1000h & 03 & 7,0 \\
Acima de $1000 \mathrm{~h}$ & 04 & 9,3 \\
\hline
\end{tabular}

Com base na Tabela 3, é possível afirmar-se que não somente todos os cursos possuem alguma disciplina em PT\&O, mas uma boa parte ( 30 cursos ou $69,8 \%$ ) possui mais de 4 componentes curriculares relacionados a esse campo, podendo haver até 15 disciplinas desse

\footnotetext{
1 Ainda há de se ponderar que essa característica das informações contidas no Bloco III (práticas profissionais) poder ser reflexo de uma desestruturação mais ampla do próprio curso quanto a essa questão, do que algo específico a PT\&O.
}

tipo, chegando a ocupar $200 \mathrm{~h}$ da carga horária total em $72,1 \%$ dos cursos. A Tabela 3 permite também algumas considerações acerca da possível existência de um grupo de cursos que se destaca frente aos demais quanto à dedicação que possuem à $\mathrm{PT} \& \mathrm{O}$ em seus currículos. Como se pode notar, 14 cursos possuem mais de sete disciplinas nesse campo, e 19 reservam mais de $400 \mathrm{~h}$ à PT\&O.

Ainda sobre o tópico das disciplinas ligadas à Psicologia do Trabalho e das Organizações, há uma prevalência de componentes curriculares que priorizam os fundamentos teórico-metodológicos (63\% das disciplinas), procedimentos para a investigação científica e a prática profissional $(34,9 \%)$; e uma referência mediana às práticas profissionais $(26,4 \%)$ e a fenômenos e processos psicológicos $(23,2 \%)$. Os componentes referentes à fundamentação epistemológica e histórica $(16,7 \%)$ e à interface com campos afins do conhecimento $(11,4 \%)$ são os menos representados.

Comparando os achados desta pesquisa com outros trabalhos é possível afirmar que o cenário é favorável à PT\&O. Enquanto que nos escritos de Zanelli (1995), Pfromm Neto (1990) e Iema (1999), o espaço ocupado pela PT\&O era ínfimo (podendo, na década de 1990, chegar a apenas uma disciplina no curso), no presente estudo já se percebe que, em média, os cursos dedicam $10 \%$ da sua carga horária a esse campo. Contudo, é certo que essa mudança era gestada em momentos precedentes à implantação da $\mathrm{DCN}$, sendo potencializadas por essas novas recomendações. Dois estudos conduzidos na década de 2000 sinalizavam para achados semelhantes ao desta pesquisa, sugerindo que as mudanças em discussão foram acontecendo gradual e progressivamente. Primeiro, o de Botelho (2003), que indica uma média de 4,3 disciplinas por cursos, um ponto e dois décimos a menos do que a média encontrada aqui $(5,5)$. Segundo, o de Morello Filho (2004) - o qual, semelhantemente à presente pesquisa, encontra uma média de $10 \%$ da carga horária do curso dedicada à $\mathrm{PT} \& \mathrm{O}$.

Tendo delimitado o espaço que a PT\&O possui, ainda resta definir o que desse campo é integrado à formação do psicólogo. Para tanto, a Tabela 4 evidencia as categorias levantadas em todo o texto descritivo do PPC, independente do bloco temático analisado.

A partir de uma análise global dos dados apresentados pela Tabela 4, depreende-se algumas conclusões. Quanto ao foco de atuação dos psicólogos em PT\&O, é evidente a preocupação da sua inserção no campo da saúde e da qualidade de vida. É certo que a recorrência do tema não é algo específico desse campo, mas reflete um movimento mais amplo ocorrido dentro da própria categoria de psicólogos. 
TABELA 4

Categorias e subcategorias referentes ao texto descritivo do PPC

\begin{tabular}{|c|c|c|c|}
\hline Eixo & Categoria & Subcategoria & $N^{o}$ de casos \\
\hline \multirow[t]{10}{*}{ Perfil do egresso } & \multirow[t]{4}{*}{ Foco da atuação } & Promoção da qualidade de vida & 17 \\
\hline & & Promoção da saúde e qualidade de vida & 08 \\
\hline & & Promoção da saúde & 07 \\
\hline & & Promoção da saúde e educação & 02 \\
\hline & \multirow[t]{3}{*}{ Local de trabalho } & Mundo do trabalho (genérico) & 08 \\
\hline & & Organizações tradicionais & 07 \\
\hline & & Sindicatos, movimento social e nas políticas públicas & 06 \\
\hline & \multirow[t]{3}{*}{ Postura do profissional } & Atuação inter, multi e transdisciplinar & 04 \\
\hline & & Atuação diversificada nas organizações & 01 \\
\hline & & Centralidade do trabalho para o sujeito & 01 \\
\hline \multirow{8}{*}{$\begin{array}{l}\text { Competências e } \\
\text { habilidades }\end{array}$} & \multirow[t]{2}{*}{ Voltadas ao mundo do trabalho } & Analisar o cenário local do campo do Trabalho & 01 \\
\hline & & Criar políticas para diversos espaços & 01 \\
\hline & \multirow[t]{4}{*}{ Voltadas às organizações } & Analisar o ambiente organizacional & 21 \\
\hline & & Administrar e gerenciar & 19 \\
\hline & & Diagnosticar processos & 16 \\
\hline & & Realizar atividades ligadas à gestão (de pessoas) & 08 \\
\hline & \multirow[t]{2}{*}{ Voltadas aos trabalhadores } & Analisar as interações interpessoais e seu impacto no sujeito & 04 \\
\hline & & Atuar na qualificação dos trabalhadores & 02 \\
\hline \multirow[t]{8}{*}{ Processo formativo } & \multirow[t]{2}{*}{ Considerações sobre a PT\&O } & PT\&O como área tradicional da Psicologia & 04 \\
\hline & & Importância da $\mathrm{PT \& O}$ na formação & 03 \\
\hline & \multirow[t]{6}{*}{ Conteúdos privilegiados } & Subjetividade e trabalho & 04 \\
\hline & & Saúde do trabalhador & 03 \\
\hline & & Aprendizagem organizacional e treinamento & 02 \\
\hline & & Aspectos do mundo do trabalho & 01 \\
\hline & & Psicologia Social do Trabalho & 01 \\
\hline & & Avaliação e processos de gestão & 01 \\
\hline \multirow[t]{2}{*}{ Justificativa do curso } & Profissional & Demanda local por profissionais da área & 04 \\
\hline & Acadêmico & PT\&O como campo essencial da Psicologia & 01 \\
\hline \multirow[t]{7}{*}{ Atividades do estágio } & \multirow[t]{2}{*}{ Nível técnico } & Seleção e treinamento & 02 \\
\hline & & Intervenção em grupos & 01 \\
\hline & \multirow[t]{5}{*}{ Nível estratégico e político } & Programas de saúde mental e qualidade de vida & 05 \\
\hline & & Desenvolvimento das relações interpessoais & 03 \\
\hline & & Gestão de recursos humanos & 01 \\
\hline & & Consultoria & 01 \\
\hline & & Implantação de programas de mudanças & 01 \\
\hline
\end{tabular}

Nota: Optou-se por, nesse momento, realizar uma distinção entre o perfil do egresso e as competências e habilidades, tendo em vista a organização do próprio documento, os quais destacam claramente as competências, permitindo o seu tratamento a parte. Contudo, essa diferenciação, não invalida análises anteriores que aglutinam essas categorias.

O marco para a consolidação dessas transformações é a Resolução n ${ }^{\circ} 218$ do Conselho Nacional de Saúde, em 1997, que adjetiva o psicólogo como um profissional da saúde. Essa orientação abriu espaço para discussões relativas à saúde e qualidade de vida dos trabalhadores (Sato, 2003), as quais reverberam no modo de se conceber o psicólogo na PT\&O. Se, em outras épocas, ele era considerado análogo a um profissional técnico da área de Recursos Humanos (RH) em empresas (Codo, 1989), agora novas possibilidades se abrem, não só por identificar esse profissional com as temáticas da saúde e da qualidade de vida, mas também, segundo consta nos PPCs analisados, indicar a sua inserção nas políticas públicas, sindicatos e movimentos sociais, bem como nas esferas estratégicas e políticas de ação.

Ainda na Tabela 4, quanto às competências e habilidades a serem desenvolvidas pelos estudantes, chama atenção a grande relevância conferida à análise dos ambientes organizacionais. O desenvolvimento dessa competência, por sua vez, é ressaltado nas DCNs (CNE, 2004) para os cursos de Psicologia, que define como uma das capacidades básicas do psicólogo a análise do seu contexto de trabalho. Não é por acaso que tal competência é destacada ao longo da formação: 
nas últimas décadas vem se percebendo a gradativa e acentuada inserção dos psicólogos nas instituições, passando, gradualmente, de um modelo de profissional autônomo-liberal para assalariado (Heloani, Macêdo \& Cassiolato, 2010). Nessa nova conformação, há a necessidade de o psicólogo compreender as relações de trabalho e os elementos inerentes ao seu ambiente laboral para o melhor desenvolvimento de suas ações.

Esses elementos retratam alterações no modo de se conceber a PT\&O nos cursos de Psicologia, a qual resguarda ora uma pluralidade de práticas e saberes vinculados a esse campo, ora uma tensão entre esses, ao passo em que alguns tópicos concorrem um com o outro, por conta das suas distintas afiliações ideopolíticas. De maneira mais precisa, essa diversidade de temas, possivelmente, relaciona-se à forma como os cursos analisados vêm integrando os conteúdos oriundos de cada fase da PT\&O. Tal diversidade apresentada nos textos descritivos do PPC reflete-se nas disciplinas (ver Tabela 5). Primeiramente, nota-se que os três momentos da PT\&O são contempladas nas maiorias dos cursos; depois, também se nota que há uma predominância das discussões relacionadas à Psicologia do Trabalho - essa é a única fase que possui um maior número de cursos com mais de cinco disciplinas a ela relacionadas, bem como apenas uma graduação não menciona conteúdos dessa fase.

A predominância da Psicologia do Trabalho na formação do psicólogo parece possuir múltiplas razões. Um deles é a reinvindicação histórica dos acadêmicos de $\mathrm{PT} \& \mathrm{O}$, relacionada à necessidade de os cursos coadunarem-se com as novas produções do campo, permitindo um maior alinhamento dos profissionais de Psicologia com as demandas sociais que a PT\&O vem enfrentando nas últimas décadas (Iema, 1999; Zanelli, 1994; 1995). Também é verdadeiro que nesse mesmo período, produziu-se, no interior desse campo, trabalhos compromissados com novas temáticas, principalmente, vinculadas a Psicologia do Trabalho, conforme atesta levantamentos realizados por Borges-Andrade e Pagotto (2010) e Gondim, Borges-Andrade e Bastos (2011).

Se, até agora, afirmamos, que há uma integração da Psicologia do Trabalho e das Organizações nos cursos de Psicologia, respeitando a sua própria diversidade, paira a questão sobre quais, efetivamente, são esses novos tópicos trabalhados. Sobre esse assunto, a Tabela 6 introduz os quatro assuntos mais abordados nos cursos em cada uma das fases da PT\&O.

TABELA 5

Quantidade de disciplinas por curso de acordo com os períodos históricos da PT\&O

\begin{tabular}{lcccc}
\hline & Psicologia Industrial & Psicologia Organizacional & Psicologia do Trabalho & Debates sobre a PT\&O \\
\hline Nenhuma & 11 & 07 & 01 & 09 \\
De 1 a 4 & 32 & 32 & 29 & 34 \\
De 5 a 8 & - & 04 & 11 & - \\
De 9 a 11 & - & - & 2 & - \\
\hline
\end{tabular}

TABELA 6

Lista de quatro temas mais frequentes nas disciplinas, organizados por período histórico da PT\&O

\begin{tabular}{|c|c|c|}
\hline Periodo histórico & Tema & $N^{o}$ de cursos \\
\hline \multirow{4}{*}{$\begin{array}{l}\text { Debates sobre a } \\
\text { PT\&O }\end{array}$} & História e definição da PTO & 22 \\
\hline & Papel do psicólogo nas organizações e no trabalho & 17 \\
\hline & Ética do psicólogo do trabalho & 08 \\
\hline & Pesquisa e produção de conhecimento em organizações & 05 \\
\hline \multirow[t]{4}{*}{ Psicologia Industrial } & Recrutamento e seleção & 25 \\
\hline & Treinamento, desenvolvimento, aprendizagem e educação & 24 \\
\hline & Avaliação de desempenho & 18 \\
\hline & Orientação profissional e ocupacional em organizações & 12 \\
\hline \multirow{4}{*}{$\begin{array}{l}\text { Psicologia } \\
\text { Organizacional }\end{array}$} & Teorias e modelos organizacionais & 17 \\
\hline & Diagnóstico e intervenção organizacional & 16 \\
\hline & Mudanças e desenvolvimento organizacional & 11 \\
\hline & Liderança e poder & 11 \\
\hline \multirow{4}{*}{$\begin{array}{l}\text { Psicologia do } \\
\text { Trabalho }\end{array}$} & Trabalho e saúde (mental) & 24 \\
\hline & Subjetividade e trabalho & 18 \\
\hline & Cultura e/ou clima organizacional & 15 \\
\hline & Políticas e planejamento de gestão de pessoas & 13 \\
\hline
\end{tabular}


A forte presença de debates sobre a PT\&O nos cursos ecoa, de alguma forma, as mudanças profundas que esse campo tem sofrido nos últimos tempos, já que tais temas auxiliariam os discentes a estruturar não somente o percurso histórico de desenvolvimento da $\mathrm{PT} \& \mathrm{O}$, como refletir acerca do papel desse profissional diante das novas conjunturas internas (à área) e externa (à sociedade). Ademais, os temas presentes em cada uma dessas fases retratam a permanência de tópicos tradicionais, como o tripé organizacional (recrutamento, seleção e treinamento), a preocupação em desenvolver a análise dos ambientes organizacionais (retratado pelo tópico de teorias e modelos organizações, diagnóstico, intervenção e mudança organizacional) e a proliferação de preocupações estruturais com o mundo do trabalho atual (presente nos debates sobre trabalho, saúde e subjetividade). Com isso fica posto não só uma multiplicação de temas abordados nas graduações, mas também discussões com finalidades distintas: enquanto que algumas se orientam para o preparo técnico do psicólogo, outras se preocupam em construir reflexões críticas acerca do entorno social do mundo do trabalho.

A predominância desses novos temas é algo recente nas graduações de Psicologia, já que em outros estudos, como o de Botelho (2003) e Freitas (2002), mesmo na década de 2000, o cenário ainda apontava para uma prevalência de discussões tradicionais.

\section{CONSIDERAÇÕES FINAIS}

Retornando às linhas anteriores, o seguinte cenário é esboçado: primeiramente, a Psicologia do Trabalho e das Organizações possui um espaço considerável dentro da formação do psicólogo; segundo, essa integração tende a abarcar uma grande diversidade de temas, oriundos de épocas distintas desse campo. Assim, atualmente, os cursos conseguem refletir em grande parte tanto os avanços desse campo, como também as tensões e dilemas que ele vive. Contudo, deve-se levar em consideração que esse estudo possui limitações tanto no que se refere à abrangência de casos analisados, como também à própria fonte das informações. No primeiro caso, a estratégia de amostragem utilizada impõe limites para generalização, sendo talvez prudente tomar os resultados aqui reportados como ilustrações de possibilidades desenvolvidas pela área na formação do psicólogo no Brasil. Todavia, é importante registrar que o fato de a amostragem ter, minimamente, preservado as características gerais dos cursos e instituições no Brasil faz com que essa limitação seja minimizada.

No que diz respeito à fonte da informação, os PPCs, embora consistindo de documentos norteadores da formação proposta, constituem aspectos de conteúdo prescrito, ao passo que há diversos outros elementos envolvidos no processo de formação - por exemplo, o modo como cada professor interpreta as instruções prescritas varia conforme sua experiência e condições específicas da relação ensino-aprendizagem. Portanto, a análise aqui proposta consiste de um retrato parcial da complexa e dinâmica formação acadêmica propiciada aos futuros psicólogos.

As limitações anteriores não impedem, contudo, que se faça, a partir dos achados aqui descritos, uma projeção positiva para esse campo quanto à ampliação de formas de atuar. Na última pesquisa sobre a atividade profissional dos psicólogos, constatou-se que aqueles vinculados à $\mathrm{PT} \& \mathrm{O}$ ainda localizavam-se em atuações técnicas e em espaços tradicionais, sem refletir os avanços desse campo (Gondim, Bastos \& Peixoto, 2010). Contudo, como Coelho-Lima, Costa e Yamamoto (2011) apontaram, para diversos autores, algumas limitações da expansão da atuação dos psicólogos em PT\&O advêm do despreparo desses profissionais. Desse modo, as mudanças ocorridas no interior da formação do psicólogo, especificamente quanto ao trato da PT\&O, possui a potencialidade de viabilizar uma expansão na inserção do psicólogo em novos espaços.

Adicionalmente, o modo como os cursos vem integrando a PT\&O na formação do psicólogo institui ao menos três papeis para esses conhecimentos. $\mathrm{O}$ primeiro seria o de viabilizar o preparo mínimo do psicólogo que irá atuar diretamente nesse campo. É verdade que muitas das críticas empreendidas até então à graduação em Psicologia funda-se na incapacidade da mesma em conferir o arcabouço necessário às práticas profissionais qualificadas (Coelho-Lima, Costa \& Yamamoto, 2011). Contudo, ergue-se a questão: como exigir essa competência dos cursos de Psicologia, se estes adotam premissas generalistas? Se, por um lado, assume-se que esse modelo de formação é o mais saudável para a estruturação de uma categoria profissional flexível, capaz de enfrentar as demandas emergentes, por outro ainda parece haver dificuldades de os fundamentos mínimos para a atuação nesse campo serem trabalhados: assim como em outras épocas (retratada por Zanelli, 1995), as disciplinas continuam priorizando demasiadamente as discussões teóricas, desvinculadas da prática.

Um segundo papel para a PT\&O é o desenvolvimento da capacitação do psicólogo de analisar o seu contexto de trabalho, independente de sua área de atuação. Como reflexo da atual conformação do campo profissional dos psicólogos (assalariados e vinculados a instituições), os conhecimentos desse campo passaram a ser centrais, não somente para aqueles que almejam atuar em PT\&O, mas para os demais psicólogos também. 
O último papel identificado extrapola o campo da técnica e se localiza na capacidade de as discussões mais recentes da PT\&O contribuírem para uma compreensão diferenciada do ser humano e da sociedade atual. Ao tratar da vinculação entre o trabalho, a saúde mental e a subjetividade, a PT\&O contribui para a construção de uma concepção de humanidade que escapa ao "subjetivismo", incorporando as condições materiais, concretas e objetivas que estão na base da compreensão da vida social humana. Além disso, esses conhecimentos também revelam as limitações e os efeitos deletérios do trabalho sob a égide do modo de produção capitalismo, auxiliando não somente a compreensão desse contexto, mas também produzindo saberes com fins a transformação social.

Por fim, diante dos achados dessa pesquisa, se para Borges (2010) a Psicologia do Trabalho e das Organizações floresce no Brasil, é certo que, na formação do psicólogo, essa primavera desponta em diversos tons.

\section{REFERÊNCIAS}

Borges, L. O. (2010). A Psicologia do Trabalho e das Organizações no Brasil floresce? Estudos de Psicologia, 15(3), 277-279.

Borges, L. O., Oliveira, A. C. F., \& Morais, L. T. W. A. (2005). O exercício do papel profissional da Psicologia Organizacional e do Trabalho. Revista Psicologia: Organizações e Trabalho, 5(2), 101-139.

Borges-Andrade, J. E. \& Pagotto, C. P. (2010). O estado da arte da pesquisa brasileira em Psicologia do Trabalho e Organizacional. Psicologia: teoria e pesquisa, 26(n. esp.), 37-50.

Botelho, A. S. O. (2003). Estudo exploratório-descritivo sobre a formação do psicólogo do trabalho no Brasil. Dissertação de mestrado, Universidade Católica Dom Bosco, Campo Grande.

Campos, D. C. \& Romaro, R. A. (2008). Os estágios em Psicologia Organizacional e Psicologia do Trabalho tal como acontecem: com a palavra a coordenação de estágio. In D. C. Campos (Org.). Atuando em Psicologia do Trabalho, Psicologia Organizacional e Recursos Humanos (pp. 10-14). Rio de Janeiro: LTC.

Codo, W. (1989). O papel do psicólogo na organização industrial (notas sobre o "lobo mau" em Psicologia). In S. T. M. Lane \& W. Codo (Orgs.). Psicologia Social: o homem em movimento (pp. 195-202). São Paulo: Brasiliense.

Coelho-Lima, F., Costa, A. L. F., \& Yamamoto, O. H. (2011). O exercício profissional do psicólogo do trabalho e das organizações: uma revisão da produção científica. Revista Psicologia: organizações e trabalho, 11(2), 21-35.

Conselho Nacional de Educação - CNE. Câmara de Educação Superior. (2004, 19 de fevereiro). Diretrizes curriculares nacionais para os cursos de graduação em psicologia: Parecer CNE/CES no. 62/2004. Brasília, DF.

Freitas, S. M. P. (2002). A Psicologia no contexto do trabalho: uma análise dos saberes e dos fazeres. Dissertação de mestrado, Pontifícia Universidade Católica do Rio Grande do Sul, Porto Alegre.
Gondim, S. M. G., Bastos, A. V. B., \& Peixoto, L. S. A. (2010). Áreas de atuação, atividades e abordagens teóricas do psicólogo brasileiro. In A. V. B. Bastos \& S. M. G. Gondim (Orgs.). O trabalho do psicólogo no Brasil (pp. 174-199). Porto Alegre: Artmed.

Gondim, S. M. G., Borges-Andrade, J. E., \& Bastos, A. V. B. (2010). Psicologia do Trabalho e das Organizações: produção científica e desafios metodológicos. Psicologia em Pesquisa, 4(2), 84-99.

Heloani, R., Macêdo, K. B., \& Cassiolato, R. (2010). O exercício da profissão: características gerais da inserção profissional do psicólogo. In A. V. B. Bastos \& S. M. G. Gondin (Orgs.). $O$ trabalho do psicólogo no Brasil (pp. 107-130). Porto Alegre: Artmed.

Iema, C. R. D. (1999). Um estudo teórico sobre a formação do psicólogo organizacional no Brasil. Psicologia: teoria e prática, 1(1), 31-41.

Morello Filho, O. (2004). Um estudo sobre a formação do aluno em Psicologia Organizacional. Dissertação de Mestrado, Centro Universitário Capital, São Paulo.

Pfromm Neto (1990). Psicologia: introdução e guia de estudo. São Paulo: EPU.

Rocha Jr, A. (1999). Das discussões em torno da formação em Psicologia às Diretrizes Curriculares. Psicologia: teoria $e$ prática, 1(2), 3-8.

Sampaio, J. E. (1998). Psicologia do trabalho em três faces. Em I. B. Goulart \& J. R. Sampaio (Orgs.). Psicologia do Trabalho e Gestão dos Recursos Humanos: estudos contemporâneos (pp. 19-40). São Paulo: Casa do Psicólogo.

Sato, L. (2003). Psicologia, saúde e trabalho: distintas construções dos objetos "trabalho" e "organizações". In Z. A. Trindade, \& Â. N. Andrade (Orgs.). Psicologia e saúde: um campo em construção (pp. 167-178). São Paulo: Casa do Psicólogo.

Seixas, P. S. (2014). A formação graduada em Psicologia no Brasil: reflexão sobre os principais dilemas em um contexto pós$D C N$. Tese de Doutorado, Universidade Federal do Rio Grande do Norte, Natal.

Seixas, P. S., Coelho-Lima, F., Silva, S. G., \& Yamamoto, O. H. (2013). Projeto Pedagógico de Curso e formação do psicólogo: uma proposta de análise. Psicologia Escolar e Educacional, 17(1), 113-122.

Zanelli, J. C. (1986). Formação e atuação em Psicologia Organizacional. Psicologia: ciência e profissão, 6(1), 31-32.

Zanelli, J. C. (1995). Formação e atuação do psicólogo organizacional: uma revisão da literatura. Temas em Psicologia, 1 , 95-107.

Zanelli, J. C. \& Bastos, A. V. B. (2004). Inserção profissional do psicólogo nas organizações e no trabalho. In J. C. Zanelli, J. E. Borges-Andrade \& A. V. B. Bastos (Orgs.). Psicologia, organizações e trabalho no Brasil (pp. 466-491). Porto Alegre: Artmed.

\section{Autores:}

Fellipe Coelho-Lima - Mestre, Universidade Federal do Rio Grande do Norte. Pedro Fernando Bendassolli - Doutor, Universidade Federal do Rio Grande do Norte.

Oswaldo Hajime Yamamoto - Doutor, Universidade Federal do Rio Grande do Norte.

\section{Endereço para correspondência:}

Fellipe Coelho-Lima

E-mail: fellipecolholima@gmail.com

Recebido em: 18.09.13

Aceito em: 10.06 .14 